\title{
Physics in Iceland
}

\section{T.I. Sigfusson, Reykjavik}

(University of Iceland)

Physics as a well defined profession in Iceland is perhaps not more than a quarter of a century old. Its history is that of the modernization of the post war period and only a handful of names were involved in the first half of its life.

The reason for the nascent nature of physics in Iceland is strongly related to the small population of the country (240000) and the fact that only in recent decades has the country been counted among the industrially developed nations.

When the Editor of Europhysics News asked me to write a few lines on aspects of physics in Iceland. I thought that physicists living in, what we could call other peripheral countries of the EPS, might recognize the common problems faced by physics in these communities. What follows here is a personal view of a physicist who returned to his country after nearly a decade abroad (Copenhagen and Cambridge), and subsequently spent three years helping to develop facilities for research here in Iceland.

\section{The Physics Community}

The community of Icelandic physicists consists of about 170 people which makes the ratio of physicists to the rest of the population very high, even by European standards. Over half of this number belong to the Icelandic Physical Society which was founded in 1977 by 34 members and is growing rapidly. In 1982 it became a member of the EPS. The membership is generally regarded as a potentially important link to the main streams of European physics.

The first Icelandic physicists studied in Europe, particularly in Denmark and Germany. These physicists had to lay the foundations for Icelandic physics which was officially inaugurated by the opening of a physics laboratory in 1957. The small but dedicated laboraroty was housed in the basement of the main university building of the University of Iceland which was founded in 1911.

\section{Geophysics: The Tradition}

Very naturally the first physics in Iceland was largely centred on some of the unique facilities the country has to offer and geophysics was to become the "tradition" of Icelandic physics. The major techniques used in research employed the physics of stable and unstable isotopes together with geomagnetism.

Geophysics continues to thrive in Iceland and its influence is most clearly felt in the harnessing of geothermal and hydroelectric energy. Through this work it is fair to say that physics has gained some respect in society. The output, in terms of papers, is considerable. A glance at the weighted number of geophysics papers written every year in the country shows that it outnumbers that of, for example, some of the Scandinavian countries, even by half an order of magnitude.

Geophysics is centred around two institutions: The Geophysics Section of the University (Science Institute) where about half a dozen physicists are working, and The National Energy Authority, where about 20 physicists with different educational backgrounds are working. Major areas of interest include aspects of geothermal energy, geomagnetism, seismology and glaciology.

\section{Other Fields}

Other disciplines of physics are represented in much smaller numbers with often only one or two persons working in each field. This part of physics is almost entirely confined within the University and includes about 10 physicists with a wide spectrum of interests. Unfortunately, however, the situation with one or two persons spanning a whole field gives rise to "critical mass effects", and may be the prime reason for lack of progress in some areas. Another reason for small output is the difficulty of funding for fundamental research. I believe that our industrial society has not yet reached the stage in its development when fundamental research is seen as the natural predecessor of applied science. At least our politicians are finding it difficult to come to terms with such views.

Areas of interest in physics within the Department are mathematical physics, cosmology, history of physics, optics and condensed matter physics. Many of these areas are led by the work of temporary research fellows. Into the more applied category fall the physics of isotopes, alternative energy research, optics and parts of condensed matter.

\section{Funding of Research}

Research in fundamental physics is funded by direct Government grants and the Icelandic Science Foundation. Only a small part of applied physics is funded by industry but there are signs that the situation may be changing. The highest ISF grant last year amounted to about $\$ 16000$ and was given for the development of research facilities in low temperature condensed matter physics. This discipline has been growing considerably over the past years and it is seen as one which, in principle, should be able to produce fundamental research and have important direct industrial implications.

The limited volume of funds available dramatically reduces the scope of experimental physics and will of course almost totally exclude some branches of physics. The priority given to research in condensed matter physics, optics and isotope physics has partly grown out of financial considerations. On the other hand, in a small community like ours the importance of individuals is quite vital. Able individuals will therefore count heavily in any priority list drawn up.

In a situation like ours, with limited funds and manpower, I believe that in organising research, it is crucial to have clearly in mind the critical mass effects of both staff and funds.

\section{Physics Education}

The teaching of the University is directed towards a B.Sc. degree in physics and geophysics. Also physicists provide instruction in physics for larger groups of mechanical and electrical engineers as well as other sciences. There are about 25 students in the Physics Department. Until now it has been thought to be more beneficial for students to go abroad to obtain graduate training and until now students have only been able to do special one year projects after B.Sc. Latterly there has been increased discussion about graduate degrees and it is hoped that improved research facilities will permit an extension of the education to include full graduate training in the near future.

On the one hand I believe it was wise not to consider graduate training here in the early days of the Department; the result has been that the teaching has been striving towards high quality undergraduate education. On the other, research has undoubtedly suffered because of this arrangement and would be much invigorated by the incorporation of graduate programmes.

\section{Contacts Abroad}

One great strength of our system is the fact that the large majority of physi- 
cists who work in Iceland have received their education and training in different countries around the world. Indeed, many Icelandic physicists are working continuously abroad. This means that the Icelandic school of physics grows out of a multitude of influences from various educational and research institutions. When brought together the various schools of thoughts are stirred together and we hope that some Darwinian process of natural selection takes place!

An inspection of the background of physicists affiliated with the University shows that most of them have British or Danish degrees, the others German, American, Norwegian and Swedish. For this reason among others I think it is difficult to compare our school of physics with any other and perhaps it would be correct to say that there is no domestic style or school characterising it.

Contacts with foreign scientists and institutions is a factor of crucial importance to physics here. It has led to new areas of exploration and research and has made it possible for physicists to work abroad on a temporary basis. Furthermore, the contacts have involved loans of expensive experimental apparatus and even donations of instruments. Generally, such contacts have helped us to follow the rapid development in various branches of the science.

\section{The Generation Gap}

The University of Iceland is like most other European universities suffering from the effects of the economic recession. The younger generation of physicists is badly hit by this crisis; vacant positions are scarce and new ones simply not created. The effect is a large pileup of competent physicists queueing for positions. This comes at a very sensitive moment in the development of Icelandic physics and may have serious consequences for future development.
Many young physicists take $U$-turns in their careers and take up jobs in less related areas although industry is gradually opening up possibilities. Physicists have had to prove that they are "just as good as" engineers who have dominated the market for a long time. Every year there are clear signs that physicists are taking on new jobs in industry, medical physics and administration and doing it successfully. It is sometimes stated that physics as a profession is just on the point of gaining a permanent status in industry.

\section{The Test}

In the coming years the big test for physics in Iceland is going to be the attempt to enhance research in non-applied physics and generate more funding from industry. The University has given semi-official priorities to a few lines of research which ought to lead to the formation of research groups and thereby overcome the critical mass problem.
Seen in the wider context of the EPS, our problems will undoubtedly be felt in other communities of the Society. And, of course, some of these considerations apply to most member countries. I believe that EPS can be instrumental in analysing and perhaps solving some of the problems on the basis of mutual assistance. Therefore, I suggest that the development of physics in the peripheral communities of EPS should be given much more attention by the Society. One way to come to grips with the subject would be to organise a special conference or include the topic in future EPS conferences.

In conclusion, let me add that surely few things can be more enjoyable than establishing a branch of science in a new environment. I also remain optimistic about the future of physics and its key role in technological society. At the same time I realize that much work is yet to be done.

\section{The nuclear physics section of NIKHEF, The Ne- 1) therlands' National Institute for Nuclear and High- Energy Physics, has openings in the PIMU group for \\ two experimental physicists}

at the postdoc level, who are interested in participating in the research of the group on pion absorption in nuclei and on pion charge exchange in pionic atoms. The experiments are performed at the pion/muon facility in Amsterdam and in some cases abroad.

Several years of research experience in nuclear or (intermediate energy) particle physics are required, while a strong background in particle detection techniques and/or data processing (Hardware/Software) is desirable.

The duration of one of the contracts is two years. The other is for one year with a possibility of one year prolongation. The appointment will be with the Foundation for Fundamental Research on Matter (FOM). Information can be obtained from

Dr. R. van Dantzig, tel. (20) 5920120 or 5922008.

Candidates are invited to apply within a month after the appearance of this advertisement, enclosing a curriculum vitae, and mentioning research performed and names of referees, to

Prof. Dr. G. van Middelkoop, Scientific Director of NIKHEF, Section K, Postbox 41882, NL-1009 DB Amsterdam.

Europhysics News is the official journal of the European Physical Society which comprises 29 National Societies, Academies and Group, over 3500 Individual Members and 66 Associate Members. Governing bodies of EPS are the General Meeting, Council and an elected Executive Committee responsible for detailed policy. EPS promotes the collaboration of physicists throughout Europe, organising and harmonising conferences and publications, improving physics education, encouraging physics applications, awarding scholarships to sponsored schools in Erice. EPS publishes in addition to EN, Europhysics Conference Abstracts, E. Ed. News and, in collaboration with The Institute of Physics (UK). the European Journal of Physics. Individual Members receive EN free of charge (price to institutions: Sw.Fr. 90 - -la), rebates on the price of many publications and on conference fees. Annual EPS membership fee for Individual Members belonging to an EPS member society is: Sw.Fr. 40.; independent members: Sw.Fr. 120.-; members of a Collaborating Society, e.g. the American Physical Society: Sw.Fr. 50.- (\$ 25).

Editor: E.N. Shaw
Meetings Compilation: W.S. Newman
Editorial Board:
K. Appert, A. Baratoff, B. Jacrot.
G.R. Macleod, M. Mayor, J. Muller
Editorial and Advertising Office at the EPS
Secretariat
Address: EUROPEAN PHYSICAL SOCIETY
P.O. Box 69 ,
\[ \begin{array}{l}\text { CH-1213 Petit-Lancy } 2 \\ \text { Switzerland }\end{array} \]
Telephone: Geneva (22) 931130
Telex: 423455 dema ch
Cables: europhys genève
Printed by: Pfirter frères sa
CH-1213 Petit-Lancy/Switzerland

